OPEN ACCESS

Edited by:

Ruixue Huang

Central South University, China

Reviewed by:

M. Jahangir Alam,

University of Houston, United States

David Paige Gilkey,

Colorado State University,

United States

*Correspondence:

Johannes K. Knobloch

j.knobloch@uke.de

Specialty section:

This article was submitted to Environmental health and Exposome,

a section of the journal

Frontiers in Public Health

Received: 27 October 2020

Accepted: 02 February 2021

Published: 23 February 2021

Citation:

Knobling B, Franke G, Klupp EM, Belmar Campos $C$ and Knobloch JK (2021) Evaluation of the Effectiveness of Two Automated Room

Decontamination Devices Under Real-Life Conditions.

Front. Public Health 9:618263.

doi: 10.3389/fpubh.2021.618263

\section{Evaluation of the Effectiveness of Two Automated Room Decontamination Devices Under Real-Life Conditions}

\author{
Birte Knobling, Gefion Franke, Eva M. Klupp, Cristina Belmar Campos and \\ Johannes K. Knobloch*
}

Institute for Medical Microbiology, Virology and Hygiene, University Medical Center Hamburg-Eppendorf, Hamburg, Germany

To evaluate the effectiveness of automated room decontamination devices, a common aerosolized hydrogen peroxide (aHP) as well as a recent gaseous ozone-based device, which produces the disinfectant reagent without the need of consumables, were tested under real-life conditions. Twenty-two contaminated surfaces were positioned in different areas in a patient room with adjacent bathroom and anteroom. Following the decontamination process bacteria were recovered and reduction factors were calculated after performing quantitative culture. Following the manufactures instructions, the ozone-based device displayed a bactericidal effect $\left(\log _{10}>5\right)$, whereas the aHP system failed for a high bacterial burden and achieves only a complete elimination of a realistic bioburden $\left(\log _{10} 2\right)$. After increasing the exposure time to $30 \mathrm{~min}$, the aHP device also reached a bactericidal effect. Nevertheless, our results indicate, that further research and development is necessary, to get knowledge about toxicity, efficacy and safety by using in complex hospital conditions and achieve meaningful integration in cleaning procedures, to reach positive effects on disinfection performance.

Keywords: automated room disinfection, hydrogen peroxide, ozone, real-life condition, terminal cleaning and disinfection, non-touch room decontamination

\section{INTRODUCTION}

Pathogens associated with common nosocomial infections like methicillin resistant Staphylococcus aureus, vancomycin-resistant enterococci or Clostridioides difficile can survive on dry surfaces for several weeks to month (1). Furthermore, these pathogens are often detected in patient's environment, if patients are colonized or infected (2-5). Contaminated surfaces might be an important source for transmission and acquisition of healthcare associated pathogens (5-8). This recognition is supported by recent studies, which pointed out an increased risk of acquiring these pathogens with possible subsequent healthcare associated infections, if prior room occupants had already been infected (9-12).

Regular cleaning such as terminal cleaning and disinfection of surfaces, have been implemented in hospitals in the past to reduce the risk of transmission by contact to inanimate surfaces $(13,14)$. However, various studies have demonstrated that adequate disinfection from routine daily cleaning was not achieved. Using a fluorescence method, Carling et al. showed that only an average of $48 \%$ of examined surfaces were cleaned successfully (15). In addition, another study demonstrates 
a terminal cleaning thoroughness of average 57\% for frequently touched surfaces after patients discharge (16).

Routine disinfection depends on several human factors, such as the selection of suitable substances, complete application to all relevant surfaces, compliance with the required exposure time, and correct implementation of cleaning protocols. Moreover, the complex hospital environment contains areas, which are unattainable and difficult to clean (17). Furthermore, unclarified responsibilities for cleaning of special sites such as medical equipment negatively affects cleaning and disinfection success (18).

To achieve more effective results automated room disinfection systems were developed to address vulnerabilities associated with manual cleaning and improve patient safety. In hospital settings automated room disinfection devices could be an additional method of disinfection, to prevent environmental-borne transmission. Currently, aerosolized and vapored hydrogen peroxide, chlorine dioxide and ultraviolet germicidal radiation are disinfectants, which were used for room decontamination $(18,19)$. Different studies had shown the effectiveness of these agents in experimental settings (18-21). The efficacy of hydrogen peroxide has also been demonstrated in hospital settings, e.g., during outbreak situations but also in routine use (19-21). In contrast, gaseous ozone is not a common reagent, because of the need of permanent moisture to achieve effectiveness (22). Consequently, only a few studies reported using ozone for decontamination but not yet for hospital room decontamination $(21,23)$.

In our study, the disinfection performance of a recently developed, fully automated system for generating ozone from atmospheric oxygen in combination with an integrated nebulizer for controlled increase of room humidity, was compared with a commercial nebulizer for generation of aerosolized hydrogen peroxide (aHP) under realistic conditions.

\section{MATERIALS AND METHODS}

The efficacy of aHP and ozone-based devices for automated room disinfection were evaluated in a typical patient room $\left(31.89 \mathrm{~m}^{2}\right)$ with adjacent bathroom $\left(6.63 \mathrm{~m}^{2}\right)$ and anteroom $(7.11$ $\mathrm{m}^{2}$ ) as displayed in Figure 1. Aerosolized hydrogen peroxide (aHP) was produced by the Sentinel $\mathrm{H}_{2} \mathrm{O}_{2}$ Fogger system (IC Solutions Leipzig, Germany) and ozone as well as the required humidity were generated by the STERISAFE ${ }^{\mathrm{TM}}$ Pro system (STERISAFE Pro version 1.0, STERISAFE ApS, Ole Maaløe's vej 5, DK - 2200 Copenhagen). The STERISAFE ${ }^{\mathrm{TM}}$ Pro has an integrated measuring device to monitor and document the ozone concentration as well as humidity. A successful disinfection cycle is only confirmed, if the permissible limit value is exceeded. In addition, at the end of disinfection procedure an active purification phase is included to remove existing ozone by degradation to oxygen and removal of fine dust by filtration.

To prepare standardized contaminated surfaces a suspension of E. faecium ATCC 6057 with $5.0 \times 10^{7}-1.2 \times 10^{8}$ colony forming units $(\mathrm{cfu}) / \mathrm{mL}$ was produced. $20 \mu \mathrm{L}$ of this suspension was dried on ceramic tiles $(5 \times 5 \mathrm{~cm}, \# 3709 \mathrm{PN} 00$, Villeroy\&Boch,
Mettlach, Germany) to generate high and primary contaminated surfaces (HCS \& PCS). The high contaminated surfaces serve to prove a bactericidal reduction capacity of $\log 10>5$ (24). Furthermore, surfaces with low contamination were generated by a touch transfer assay, to demonstrate efficacy against a realistic bioburden (25). In brief, dried E. faecium was picked up by touching the PCS with one finger covered with a sterile cotton glove after moistening on Columbia Agar with Sheep Blood (COLS+, OXOID Deutschland GmbH, Wesel, Germany) and bacteria were transferred to another sterile ceramic tile to produce the secondary contaminated surface (SCS). Only SCS that met an initial surface load of $5 \times 10^{2}-5 \times 10^{3} \mathrm{cfu}$ were included in the final analysis.

The HCS were placed at 22 certain positions locations in the complex room structure to represent both vertical and horizontal surfaces in different heights and positions [close to patients ( $n=$ $4)$; distant from patients $(n=10)$; bathroom $(n=3)$; anteroom $(n=5)]$. Four SCS were placed close to the patient area, while two were positioned in furnishings within the patient room and bathroom (Figure 1). Also, one HCS and one SCS were placed outside the test room as controls.

Both systems for automatic room disinfection were investigated at least in four independent experiments with identical placement of contaminated surfaces. The disinfection devices were employed according to manufactures instructions. For the ozone-based device, a normal cycle with 70-80 ppm ozone concentration was applied for a holding time of $15 \mathrm{~min}$ and $80-90 \%$ relative humidity. For the aHP unit a fogging time of 20 min was used in accordance with the manufacturer's specifications depending on the volume of the test room. After insufficient decontamination performance according to manufactures instructions $(n=3)$, we increased fogging time to $30 \mathrm{~min}(n=4)$. Before application, doors and ventilation diffusers as well as smoke detectors were sealed.

After each decontamination process bacteria were recovered from both, treated and untreated ceramic tiles, by using flocked nylon swabs (eSwab ${ }^{\mathrm{TM}}$ Standard, Copan; Brescia, Italien). After moistening the swab with transport medium, the ceramic tiles were wiped in horizontal, vertical and diagonal direction while the swab was rotated continuously. The bacteria were eluted into the transport medium by vortexing for $30 \mathrm{~s}$ and subsequently quantitative cultures were performed in double determination (detection limit $5 \mathrm{cfu} / 25 \mathrm{~cm}^{2}$ ) by spreading $100 \mu \mathrm{l}$ of the Amies Medium on COLS+, using a Drigalski spatula. Agar plates were incubated for $18-24 \mathrm{~h}$ at $37^{\circ} \mathrm{C}$. The reduction factors were calculated by subtracting the $\log 10$ of the control and the $\log 10$ after disinfection. Statistical analysis was performed in R (26) by using a Bonferroni corrected pairwise $t$-test.

\section{RESULTS}

Evaluation of quantitative cultures of untreated high contaminated surfaces (HCS) showed a mean of $7.4 \times 10^{5}$ $\mathrm{cfu} / 25 \mathrm{~cm}^{2}$ for all tested devices (Figure 2A). This surface load is suitable for demonstrating a reduction of $>5 \log 10$ and was able to designate a product as a bactericidal disinfectant. The bacterial 


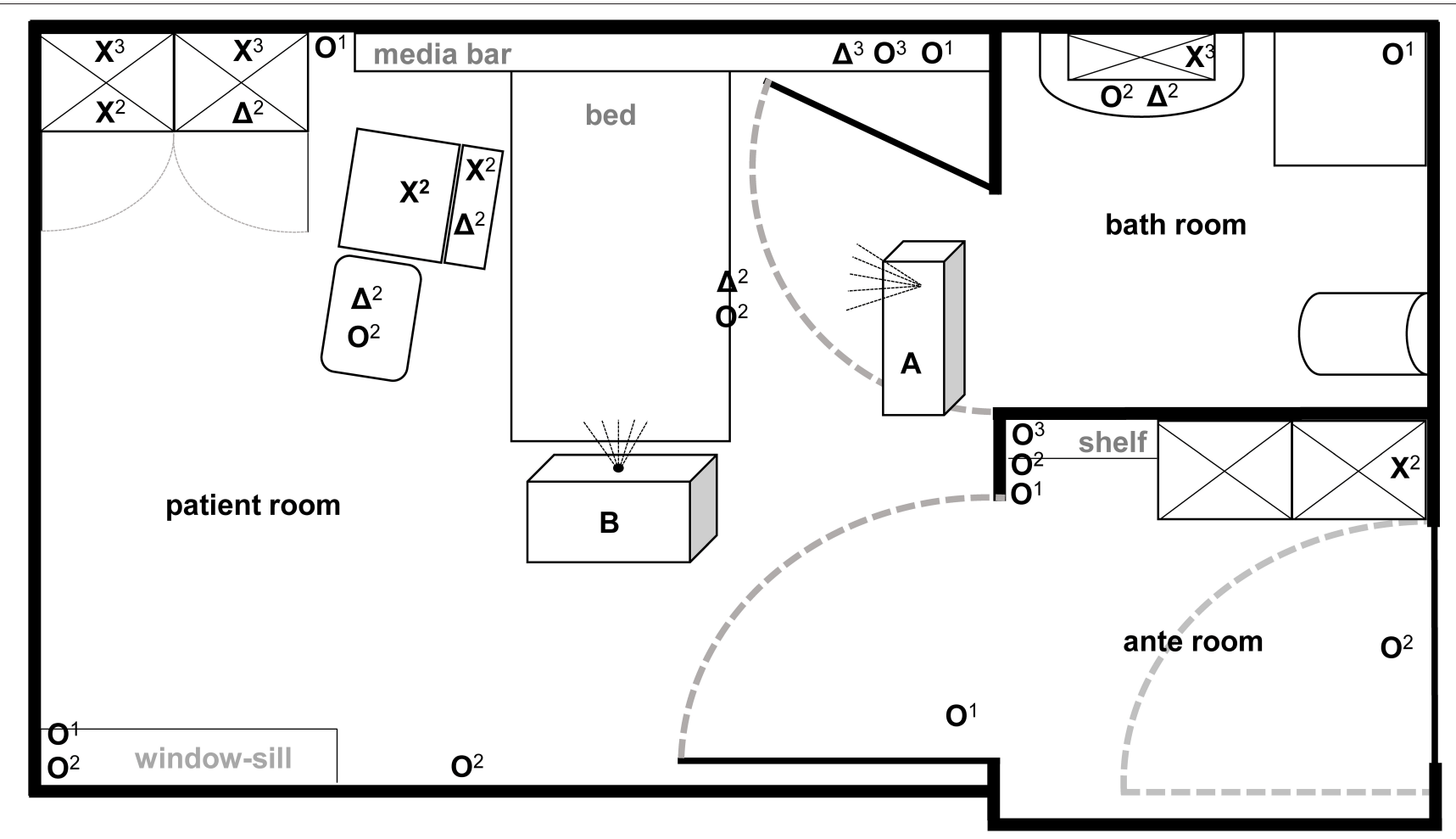

FIGURE 1 | Illustration of test room with depiction of target positions and location of automated room decontamination devices. Both test devices (A: Sentinel $\mathrm{H}_{2} \mathrm{O}_{2}$-Fogger; B: STERISAFE ${ }^{\text {TM }}$ Pro Ozone) were positioned at different spots in patient room according to manufactures instructions. The different symbols [O: high contaminated surfaces (HCS); X: HCS into furnishings; $\Delta$ : secondary contaminated surfaces (SCS)] represent the kind of contaminated surface used at particular positions. In addition, superscript numbers display the position heights into the room (1 on the ground; 2 middle level; 3 at the top).

load of untreated SCS revealed an average of $2.1 \times 10^{3} \mathrm{cfu} / 25$ $\mathrm{cm}^{2}$ modeling a worst case contamination of frequent touched surfaces $(25,27)$.

The ozone-based STERISAFE Pro achieved a $\log 10$ reduction factor of $>5$ in all parts of test room, regardless of the placement of the HCS. The total cycle time needed for one decontamination process was $\sim 3 \mathrm{~h}$. The Sentinel $\mathrm{H}_{2} \mathrm{O}_{2}$ Fogger needed about $2 \mathrm{~h}$ for one cycle, but did not achieve the reduction rate required for disinfectants, taking into account the manufacturer's instructions. Under these conditions only a mean reduction of $2 \log 10$ was observed. Strikingly, different reduction rates were achieved in the three connected rooms under these conditions. Despite the direction of the device spray into the patient's room, non-significantly lower reduction rates were observed in the patient's room with a mean reduction rate of $\log 10$ 1.73 compared to the anteroom (mean $=2.31, p>0.05$ ) and the bathroom (mean $=1.86, p>0.05$ ). Because of this, after three experiments the exposure time was increased to $30 \mathrm{~min}$ for four additional experiments. After this adaption, the Sentinel $\mathrm{H}_{2} \mathrm{O}_{2}$ Fogger achieved a $\log 10$ reduction rate of $>5$ at all test positions equally (Figure 2B). The reduction factors determined for the Sentinel $\mathrm{H}_{2} \mathrm{O}_{2}$ Fogger at $20 \mathrm{~min}$ were significantly less effective compared to the reductions achieved by Sterisafe ${ }^{\mathrm{TM}}$ Pro and Sentinel $\mathrm{H}_{2} \mathrm{O}_{2}$ Fogger at $30 \mathrm{~min}$ exposure $(p<0.01)$.
Furthermore, no bacteria could be recovered from the SCS after automated room disinfection, regardless of the device used and the amount of nebulized $\mathrm{H}_{2} \mathrm{O}_{2}$. This results in a $\log 10$ reduction factor of average $>3$. The reduction factors of the different devices are only varying in dependence of bacterial load of untreated SCS (Figure 2C). Therefore, a statistical evaluation of these results was omitted.

\section{DISCUSSION}

Manual cleaning is not standardized and often refuses to remove bioburden on frequently touched surfaces, because of different personal-related reasons $(17,18,22)$. Therefore, automated room decontamination systems could be a suitable method to enhance the success of cleaning and disinfection processes in hospitals. The efficacy of a procedure, the ease and safety of use, rapid availability and ability to be integrated into routine processes are important for using new standardized procedures for final disinfection (18). Therefore, studies characterizing such devices are essential to ensure effectivity as well as safe operation in hospitals.

The efficacy of the established aerosolized hydrogen peroxide (aHP) process was investigated in comparison to a recently developed fully automated device for disinfection 

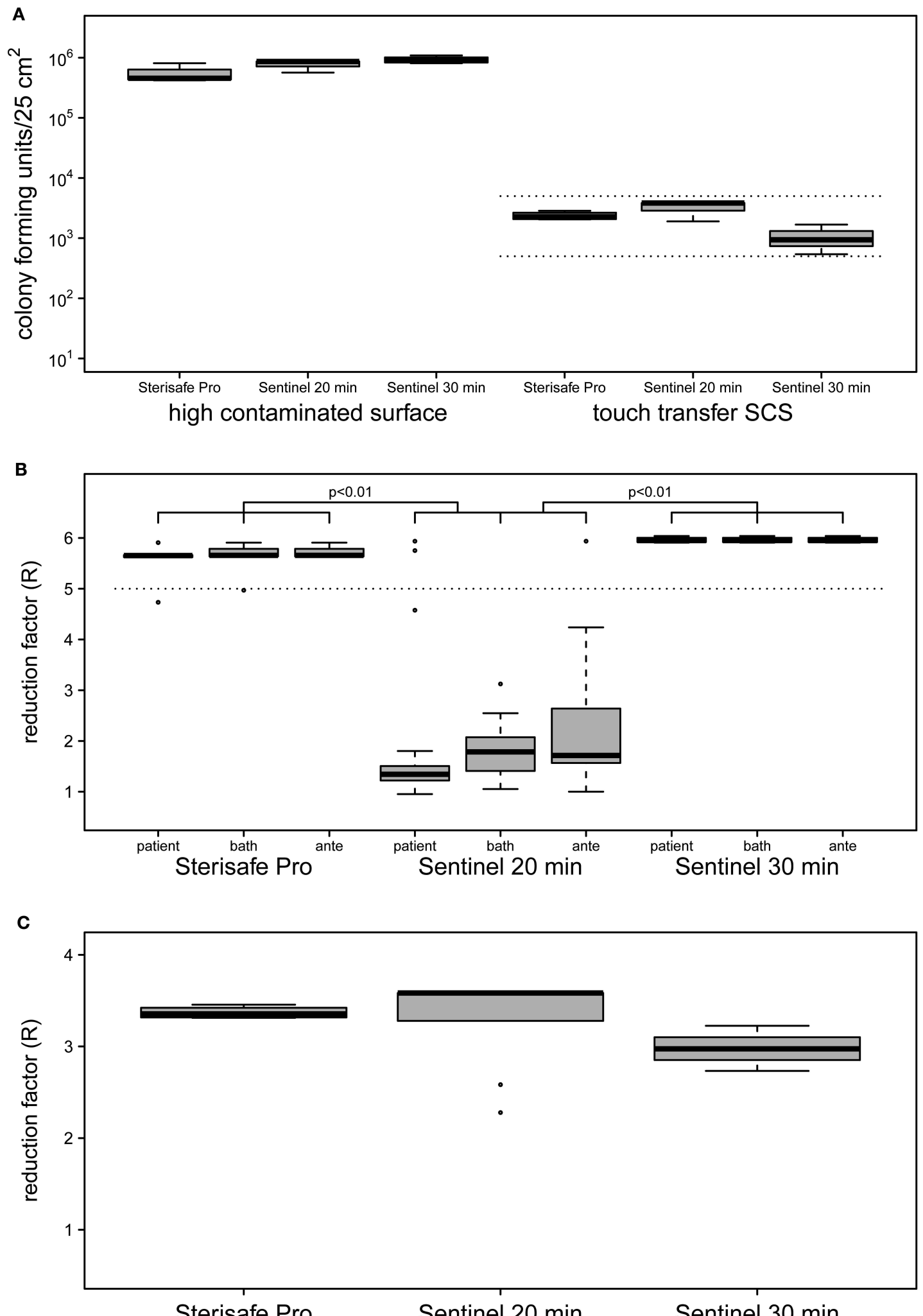

FIGURE 2 | Initial contamination of HCS and SCS surfaces (A) and reduction factors achieved by two different automated room decontamination devices (B,C). The distribution of contamination used for the experiments (A) are shown separately as boxplot for the HCS and the SCS for the equipment and processes performed. 
FIGURE 2 | Only SCS that met an initial surface load of $5 \times 10^{2}-5 \times 10^{3}$ cfu were included (dashed lines). The effectiveness of the disinfection processes was determined in several independent experiments with quantification of recoverable bacterial load in duplicate (STERISAFE ${ }^{\text {TM }}$ Pro [ $\left.n=4\right]$, Sentinel 20 min $[n=3]$, Sentinel $30 \mathrm{~min}[n=4])$. The distribution of the calculated reduction factors for the HCS (B) and the SCS (C) is shown separately as a boxplot for the patient room, the bathroom and the anteroom. Disinfection using STERISAFETM Pro as well as a 30-min nebulization of $\mathrm{H}_{2} \mathrm{O}_{2}$, achieved the mean reduction rate of 5 log 10 (B, dashed line) required for a process recognized as disinfection. Both disinfection processes were superior to a 20-min nebulization of $\mathrm{H}_{2} \mathrm{O}_{2}$, as confirmed with the $\mathrm{HCS}$ ( $p<0.01$ paired $t$-test with Bonferroni correction). Realistic bacterial contamination was completely eliminated (C) for both processes (for aHP regardless of nebulization time). The differences in the distribution of the reduction rates displayed in the boxplots, results exclusively from the differences in the contamination used (A, right side).

using ozone under conditions as close to reality as possible. All decontamination experiments were carried out in a fully furnished patient room with two adjacent rooms using highly contaminated surfaces according to the European Committee of Standardization (24) as well as surfaces with a realistic bioburden.

Both devices were used according to the manufacturer's specifications. The ozone-based device showed the required bactericidal effect with a reduction of $>5 \log 10$, while aHP did not meet the requirement with an average reduction of only 2 $\log 10$ for the high contamination. However, a realistic surface contamination, which was modeled with touch transfer, could be completely eliminated by both devices. By extending the fogging time of the aHP device and thus increasing the amount of hydrogen peroxide applied, the full disinfecting efficacy could be achieved.

The obtained results show a bactericidal effectiveness of the ozone device independent of the position in the room. Previous studies demonstrated a reduction of bacteria known to cause hospital-acquired infections by only $>3 \log 10(28,29)$. Here, an ozone concentration of $25 \mathrm{ppm}$ was applied over different exposure times and a relative humidity of $75-95 \%$. However, a reduction of $>3 \log 10$ does not meet the requirements for bactericidal disinfection performance (24). Moat et al. assume that an increase in the ozone concentration might led to the achievement of disinfecting efficacy (29). Zoutman et al. showed that a reduction $>6 \log 10$ for MRSA could only be achieved at $500 \mathrm{ppm}$ ozone concentration ( $90 \mathrm{~min}$ exposure time) at a relative humidity of $80 \%$, which was produced by a separate humidifier (30). However, enterococci were not sufficiently reduced under these conditions. Only the addition of $1 \%$ hydrogen peroxide instead of water nebulized to increase the room humidity resulted in a high efficacy with a $30 \mathrm{~min}$ exposure time (30). It was shown that an increased humidity level enhances microbiocidal efficiency (31), our results with full bactericidal efficacy are consistent with these previous data as the new system combines a controlled high relative humidity with a continuous ozone level above $70 \mathrm{ppm}$ for $60 \mathrm{~min}$. These data indicate, that full activity can be reached without the use of additional consumables (e.g., HP) if the process is controlled during the whole disinfection cycle.

The aHP system, only reaches full bactericidal effectiveness after extending the fogging time to $30 \mathrm{~min}$. This is in agreement with observations that aHP shows varying antimicrobial activity depending on the location of contaminated surfaces in the room $(17,32-34)$. Consistent with $\mathrm{Fu}$ et al. (17), we did not observe full efficacy for aHP at all positions when following the manufacturer's instructions, while full efficacy was observed at all positions with an increased amount of nebulized disinfectant.
These data indicate that experimental dose finding for an aHP system is required before routine use.

Both systems require a process time of more than $2 \mathrm{~h}$ and also require time-consuming preparation (e.g., sealing doors, air diffusers, and smoke detectors with adhesive tape) and therefore cannot be used at all times. Occupational safety aspects are welltaken into account with the STERISAFE ${ }^{\mathrm{TM}}$ Pro device, since at the end of the process the active substance is completely degraded and the concentration of ozone prevailing in the room is continuously displayed on a mobile tablet computer and recorded in a standardized manner. In contrast, there is no possibility of monitoring or logging process parameters for the simple aHP nebulizer. For such devices, it is recommended to use additional measurement equipment to verify sufficient concentration and ensure adherence to safety exposure limits afterwards (18). Both principles of action are based on reactive oxygen species that inactivate pathogens, so that sensitive materials could be attacked. However, many medical device manufacturers allow wipe disinfection with hydrogen peroxide, so material compatibility data is available for many materials. Ozone is a highly reactive and corrosive gas $(22,23)$ and in the future further investigations on material compatibility have to take place.

The following limitations of present study should be noted: The microbiocidal efficiency has only been tested for one pathogen, which is known to be environmentally-resistant. To make a general statement on the effectiveness of such devices in routine use, further investigations with other healthcare associated pathogens such as S. aureus, C. difficile, or Acinetobacter baumannii should be performed. Furthermore, the influence of soiling and organic load, which have contributed to the reduction in efficacy of automated room decontamination devices in other studies $(17,32)$, has not yet been included in our study. Additionally, tests should be carried out on various surface materials to assess the impact of different surface texture on disinfection performance.

In conclusion, both ozone-based as well as hydrogen peroxide automated room decontamination systems can achieve bactericidal effectiveness and might have a high potential to improve disinfection performance in hospitals by standardization of the process. The fact that no consumables are needed to generate ozone, could be a decisive advantage especially in pandemic situations like current Covid-19, which, was in part characterized by supply bottlenecks also of disinfectants (35). However, currently unknown aspects of safety and material compatibility as well as long decontamination cycles might restrain a routine use in terminal cleaning procedures. Therefore, additional research under real-life conditions is 
needed to confirm effectiveness against a wide variety of pathogens as well as for various environmental conditions and surfaces.

\section{DATA AVAILABILITY STATEMENT}

The original contributions presented in the study are included in the article/supplementary material, further inquiries can be directed to the corresponding author.

\section{REFERENCES}

1. Kramer A, Schwebke I, Kampf G. How long do nosocomial pathogens persist on inanimate surfaces? A systematic review. BMC Infect Dis. (2006) 6:130. doi: 10.1186/1471-2334-6-130

2. Dancer SJ. Importance of the environment in meticillin-resistant Staphylococcus aureus acquisition: the case for hospital cleaning. Lancet Infect Dis. (2008) 8:101-13. doi: 10.1016/S1473-3099(07)70241-4

3. Drees M, Snydman DR, Schmid CH, Barefoot L, Hansjosten K, Vue PM, et al. Antibiotic exposure and room contamination among patients colonized with vancomycin-resistant enterococci. Infect Control Hosp Epidemiol. (2008) 29:709-15. doi: 10.1086/589582

4. Barbut F, Menuet D, Verachten M, Girou E. Comparison of the efficacy of a hydrogen peroxide dry-mist disinfection system and sodium hypochlorite solution for eradication of Clostridium difficile spores. Infect Control Hosp Epidemiol. (2009) 30:507-14. doi: 10.1086/597232

5. Otter JA, Yezli S, French GL. The role played by contaminated surfaces in the transmission of nosocomial pathogens. Infect Control Hosp Epidemiol. (2011) 32:687-99. doi: 10.1086/660363

6. Weber DJ, Anderson D, Rutala WA. The role of the surface environment in healthcare-associated infections. Curr Opin Infect Dis. (2013) 26:338-44. doi: 10.1097/QCO.0b013e3283630f04

7. Russotto V, Cortegiani A, Raineri SM, Giarratano A. Bacterial contamination of inanimate surfaces and equipment in the intensive care unit. $J$ Intensive Care. (2015) 3:54. doi: 10.1186/s40560-015-0120-5

8. Wohrley JD, Bartlett AH. The role of the environment and colonization in healthcare-associated infections. In: McNeil JC, Campbell JR, Crews JD, editors. Healthcare-Associated Infections in Children. Cham: Springer International Publishing (2019). p. 17-36. doi: 10.1007/978-3-319-98122-2_2

9. Huang SS, Datta R, Platt R. Risk of acquiring antibiotic-resistant bacteria from prior room occupants. Arch Intern Med. (2006) 166:1945-51. doi: 10.1001/archinte.166.18.1945

10. Datta R, Platt R, Yokoe DS, Huang SS. Environmental cleaning intervention and risk of acquiring multidrug-resistant organisms from prior room occupants. Arch Intern Med. (2011) 171:491-4. doi: 10.1001/archinternmed.2011.64

11. Shaughnessy MK, Micielli RL, DePestel DD, Arndt J, Strachan CL, Welch $\mathrm{KB}$, et al. Evaluation of hospital room assignment and acquisition of Clostridium difficile infection. Infect Control Hosp Epidemiol. (2011) 32:2016. doi: 10.1086/658669

12. Mitchell BG, Dancer SJ, Anderson M, Dehn E. Risk of organism acquisition from prior room occupants: a systematic review and meta-analysis. J Hosp Infect. (2015) 91:211-7. doi: 10.1016/j.jhin.2015. 08.005

13. Garner JS, Favero MS. Guideline for handwashing and hospital environmental control, 1985 supersedes guideline for hospital environmental control published in 1981. Am J Infect Control. (1986) 14:110-26. doi: 10.1016/0196-6553(86)90019-2

14. Centers for Disease Control and Prevention. Guidelines for Environmental Infection Control in Health-Care Facilities: Recommendations of CDC and the Healthcare Infection Control Practices Advisory Committee (HICPAC). (2003). Available online at: https://www.cdc.gov/infectioncontrol/guidelines/ environmental/index.html (accessed January 06, 2021).

\section{AUTHOR CONTRIBUTIONS}

BK and JK conceived and planned the experiments. BK and GF carried out the experiments. BK, GF, EK, CB, and JK contributed to the experiments and the interpretation of the results. $\mathrm{BK}$ and JK performed the statistical analyses. BK, GF, and JK wrote the manuscript in consultation with EK and CB. All authors discussed the results and critically revised and approved the final version of manuscript.

15. Carling PC, Parry MM, Rupp ME, Po JL, Dick B, von Beheren S. Improving cleaning of the environment surrounding patients in 36 acute care hospitals. Infect Control Hosp Epidemiol. (2008) 29:1035-41. doi: 10.1086/591940

16. Carling PC, von Beheren S, Kim $\mathrm{P}$, Woods $\mathrm{C}$. Intensive care unit environmental cleaning: an evaluation in sixteen hospitals using a novel assessment tool. J Hosp Infect. (2008) 68:39-44. doi: 10.1016/j.jhin.2007.09.015

17. Fu TY, Gent P, Kumar V. Efficacy, efficiency and safety aspects of hydrogen peroxide vapour and aerosolized hydrogen peroxide room disinfection systems. J Hosp Infect. (2012) 80:199-205. doi: 10.1016/j.jhin.2011.11.019

18. Otter JA, Yezli S, Barbut F, Perl TM. An overview of automated room disinfection systems: when to use them and how to choose them. In: Otter JA, Yezli S, Barbut F, Perl TM, editors. Decontamination in Hospitals and Healthcare. Sawston: Woodhead Publishing (2020). p. 323-69. doi: 10.1016/B978-0-08-102565-9.00015-7

19. Boyce JM. Modern technologies for improving cleaning and disinfection of environmental surfaces in hospitals. Antimicrob Resist Infect Control. (2016) 5:10. doi: 10.1186/s13756-016-0111-x

20. Rutala WA, Weber DJ. Disinfectants used for environmental disinfection and new room decontamination technology. Am J Infect Control. (2013) 41:S36-41. doi: 10.1016/j.ajic.2012.11.006

21. Dancer SJ. Controlling hospital-acquired infection: focus on the role of the environment and new technologies for decontamination. Clin Microbiol Rev. (2014) 27:665-90. doi: 10.1128/CMR.00020-14

22. Otter JA, Yezli S, Perl TM, Barbut F, French GL. The role of 'no-touch' automated room disinfection systems in infection prevention and control. $J$ Hosp Infect. (2013) 83:1-13. doi: 10.1016/j.jhin.2012.10.002

23. Davies A, Pottage T, Bennett A, Walker J. Gaseous and air decontamination technologies for Clostridium difficile in the healthcare environment. J Hosp Infect. (2011) 77:199-203. doi: 10.1016/j.jhin.2010.08.012

24. European Committee for Standardization. DIN EN 14885:201910, Chemische Desinfektionsmittel und Antiseptika_- Anwendung Europäischer Normen für chemische Desinfektionsmittel und Antiseptika; Deutsche Fassung EN_14885:2018. Berlin: Beuth Verlag GmbH (2019). doi: $10.31030 / 3085857$

25. Knobloch JK-M, Tofern S, Kunz W, Schütze S, Riecke M, Solbach W, et al. "Life-like" assessment of antimicrobial surfaces by a new touch transfer assay displays strong superiority of a copper alloy compared to silver containing surfaces. PLoS ONE. (2017) 12:e0187442. doi: 10.1371/journal.pone.0187442

26. R Core Team. R: A Language and Environment for Statistical Computing. Vienna: R Foundation for statistical computing (2020).

27. Adams CE, Smith J, Watson V, Robertson C, Dancer SJ. Examining the association between surface bioburden and frequently touched sites in intensive care. J Hosp Infect. (2017) 95:76-80. doi: 10.1016/j.jhin.2016. 11.002

28. Sharma M, Hudson JB. Ozone gas is an effective and practical antibacterial agent. Am J Infect Control. (2008) 36:559-63. doi: 10.1016/j.ajic.2007. 10.021

29. Moat J, Cargill J, Shone J, Upton M. Application of a novel decontamination process using gaseous ozone. Can J Microbiol. (2009) 55:928-33. doi: 10.1139/W09-046

30. Zoutman D, Shannon M, Mandel A. Effectiveness of a novel ozone-based system for the rapid high-level disinfection of health care spaces and surfaces. Am J Infect Control. (2011) 39:873-9. doi: 10.1016/j.ajic.2011.01.012 
31. Li C-S, Wang Y-C. Surface germicidal effects of ozone for microorganisms. AIHA J. (2003) 64:533-7. doi: 10.1080/15428110308984851

32. Piskin N, Celebi G, Kulah C, Mengeloglu Z, Yumusak M. Activity of a dry mist-generated hydrogen peroxide disinfection system against methicillinresistant Staphylococcus aureus and Acinetobacter baumannii. Am J Infect Control. (2011) 39:757-62. doi: 10.1016/j.ajic.2010.12.003

33. Steindl G, Fiedler A, Huhulescu S, Wewalka G, Allerberger F. Effect of airborne hydrogen peroxide on spores of Clostridium difficile. Wien Klin Wochenschr. (2015) 127:421-6. doi: 10.1007/s00508-0140682-6

34. Ali S, Muzslay M, Bruce M, Jeanes A, Moore G, Wilson APR. Efficacy of two hydrogen peroxide vapour aerial decontamination systems for enhanced disinfection of meticillin-resistant Staphylococcus aureus, Klebsiella pneumoniae and Clostridium difficile in single isolation rooms. $J$ Hosp Infect. (2016) 93:70-7. doi: 10.1016/j.jhin.2016.01.016

35. Diederich BPS. Why is there a shortage of disinfectants during the covid-19 crisis? (2020). Available online at: https://oecd-environment-focus.blog/2020/ 05/12/why-is- there-a-shortage- of- disinfectants-during-the-covid-19-crisis/ (accessed December 16, 2020).

Conflict of Interest: BK and JK received a travel grant from INFUSER Germany GmbH, Mannheim, Deutschland.

The remaining authors declare that the research was conducted in the absence of any commercial or financial relationships that could be construed as a potential conflict of interest.

Copyright (c) 2021 Knobling, Franke, Klupp, Belmar Campos and Knobloch. This is an open-access article distributed under the terms of the Creative Commons Attribution License (CC BY). The use, distribution or reproduction in other forums is permitted, provided the original author(s) and the copyright owner(s) are credited and that the original publication in this journal is cited, in accordance with accepted academic practice. No use, distribution or reproduction is permitted which does not comply with these terms. 